\title{
Preference for complexity as a function of schematic orderliness and redundancy
}

SAM H. LANE. ${ }^{1}$ Texas Christian University, Ft. Worth, Texas 76129

Preference ratings were obtained from Ss for stimuli differing in complexity. Complexity was expressed in terms of the generating rule of the stimuli and the amount that the derived stimuli deviated from that rule. The results indicated that approximately $30 \%$ of the Ss preferred the lowest value of complexity while the other 70\% preferred the highest value of complexity. These results are discussed with reference to previous contrasting findings.

The relationship between judged stimulus complexity and stimulus preference has recently been characterized by a variety of forms. Munsinger \& Kessen (1964) reported preference in college students to be a nonmonotonic, curvilinear function of complexity with stimuli derived by a procedure developed by Attneave \& Arnoult (1956). This nonmonotonic, curvilinear relationship was also found by Hershenson, Munsinger, \& Kessen (1965) with infants and with the same type of stimuli. However, Munsinger, Kessen. \& Kessen (1964); with a sample of 6- and 7-year-old children, and Munsinger \& Weir (1967), with a sample of 9- to 41-month-old children, reported strong preferences for increasing levels of complexity. Thomas (1966) reported "... an increasing preference for complexity until midadolescence after which there tends to be a systematic change in preference for shapes of lesser complexity."

The aforementioned studies were based upon the oft-repeated postulate that an individual will prefer an intermediate level of complexity (Dember \& Earl, 1957: Berlyne, 1960). However, the work of Barron \& Welsh (1952) and Welsh (1959) suggested that there may be a wide variation in peak complexity preferences among individuals. Thus, whereas most individuals do prefer an intermediate value of complexity, that value will be highly variable within any group of Ss across any given range of complexity. This qualification of the "intermediate-level" postulate was supported by Kammann (1966) with poetry preferences, by Dorfman \& McKenna (1966) with matrix grains, and by Vitz (1966) with random shapes. In common, these studies report a wide variation in preference peaks across individual Ss.

A recent pattern generation system, the Vargus 9 (Evans \& Mueller, 1966), provides for the generation of stimuli for which various parameters relevant to information processing can be independently manipulated. These stimuli, and others similar to them, have been primarily used in studies of human learning. The use of Vargus 9 stimuli in research on complexity would allow for the planning and interpretation of studies within an established theoretical context (Evans, 1967). Thus these stimuli offer several possible benefits for research on preference for complexity.

The Vargus 9 program produces, as computer output, histoforms which have been randomly sampled from a defined population and for which information and redundancy measures have been controlled. The histoforms represent a sample made up of variants which are independent and measurable deviations from a well-defined prototype. Two advantages of this procedure over the one of Attneave \& Arnoult (1956) are that any quantity of patterns may be produced quickly and easily, and that a more precise specification and quantification of some of the variables relevant to subjective complexity is possible.
Lane \& Evans (1968) have demonstrated that with the Vargus 9 stimuli, judged complexity could be expressed as a linear function of the generating rule of the patterns and level of redundancy. Therefore. a set of stimuli was available that had been demonstrated to be perceived as proceeding from a point of lesser to greater complexity in a linear fashion.

The purpose of the present research was to examine the relationship between preference and complexity while using stimuli for which it had been demonstrated that various parameters of subjective complexity could be controlled and independently manipulated, and for which there existed an established context of theoretical interpretation. Also, the data were inspected for the possible influence of individual differences.

Subjects

\section{METHOD}

The Ss were 59 college students enrolled in introductory psychology classes.

Stimulus Materials and Procedure

The stimuli were the same Vargus 9 histoforms previously used by Lane \& Evans (1968). Briefly, these patterns were derived according to three schema rules (Schema 1, least complex: Schema 2, moderately complex: Schema 3, most complex): each at three levels of redundancy $\left(60^{\%}, 50^{\%}\right.$, and $40 \%$ ). The combination of these conditions represented nine independent values of complexity. A more complete description of the stimuli and the generation procedure may be found in Evans \& Mueller (1966). and Lane \& Evans (1968).

Eighteen patterns from each level of complexity were Xeroxed, six to a page. The resulting 27 pages were randomly arranged and assembled into booklets. The Ss were instructed that the patterns had been derived by a computer. They were asked to rate each page of patterns in terms of how much they "liked" that particular page. It was emphasized that they should consider all six patterns on a page as a group rather than make their rating on the basis of any individual pattern. The Ss were provided with a separate sheet of paper which was numbered from 1 to 27 and had seven blank spaces beside each number. The blank to the extreme left was labeled "Least" and the blank to the extreme right was labeled "Most." The Ss were told to place a check-mark in the space which corresponded to their preference rating for that group. The Ss were encouraged to inspect all of the pages before they made their rating. The responses were scored by assigning scale values of 1 through 7 to the seven spaces which corresponded to "Least" through "Most." A S's score for each condition was his average rating of the three groups of patterns from that condition.

\section{RESULTS}

The data indicated that certain individual differences indeed did exist. Scores were found to peak at either Schema 1, 60\% (least complex), or Schema 3, 40\% (most complex), and then to decline in varying degrees toward the opposite extreme. The variation in peak preferences across intermediate points in the range of complexity, which was reported by Vitz (1966) and by Dorfman \& McKenna (1966), was definitely not present. With a criterion of a Schema 1, 60\% mean rating score of less than 2.00, and a Schema 3,40\% mean rating score greater than 5.00. it was possible to separate 39 Ss who preferred a high level of complexity from the initial 59 Ss. A one-way ANOVA with repeated measures yielded an $F(8,38)=154.40, p<.001$. A trend analysis of the means indicated that $97.1 \%$ of the treatment variance could be accounted for by a linear 


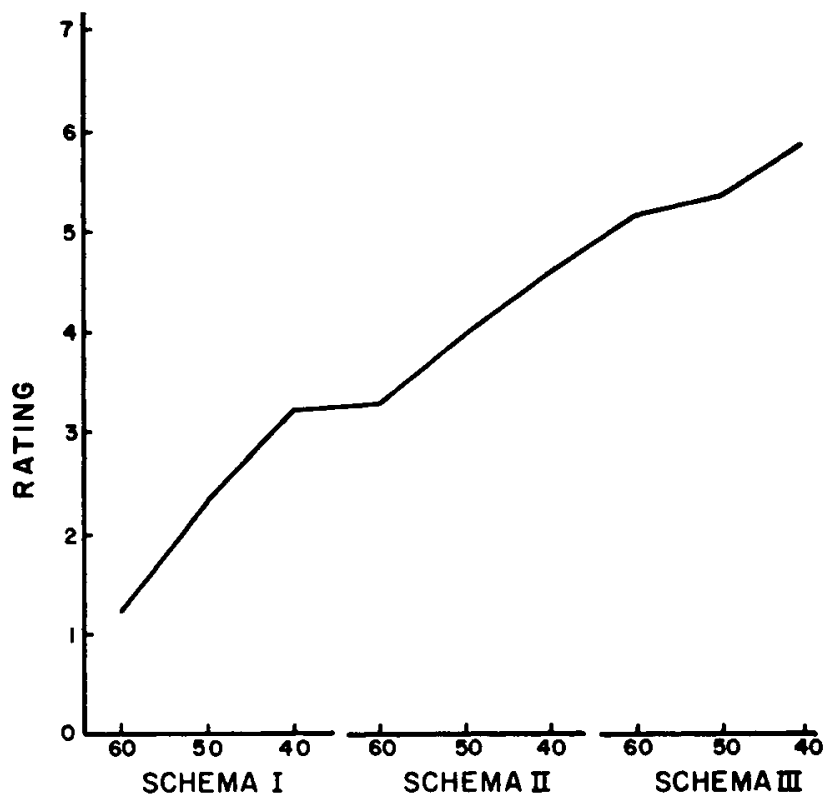

Fig. 1. The preference curve for $S s(N=39)$ who preferred the highest level of complexity.

component. It can be seen from Fig. 1 that the preference/ complexity curve is very similar to the subjective complexity function reported by Lane \& Evans (1968).

With a criterion of a Schema 3, $40 \%$ mean rating score of less than 2.00 , and a Schema $1,60 \%$ mean rating score of greater than 5.00 , it was possible to separate from the remaining $19 \mathrm{Ss}, 17 \mathrm{Ss}$ who preferred the lowest level of complexity. (Inspection of the remaining two Ss' ratings revealed no orderly trends and they were dropped from further consideration.) A one-way ANOVA with repeated measures yielded an $F(8,16)=46.93, p<.001$. A trend analysis of the means indicated that $88.1 \%$ of the treatment variance could be accounted for by a linear component, and $10.4 \%$ could be accounted for by a cubic component, both of which were significant. No significant quadratic component was found. Inspection of Fig. 2 shows this curve to be complementary to the curve in Fig. 1.

\section{DISCUSSION}

The present results indicate preference to be an increasing or decreasing linear function of increasing complexity. These results are somewhat in disagreement with the findings of Munsinger \& Kessen (1964) and Thomas (1966) with samples of a similar age range. The demonstration of only two preference points, at each extreme in the range of complexity, is in contrast to the results of Vitz (1966) and Dorfman \& McKenna (1966).

One explanation for the present results is that the Ss were choosing the extreme condition they "preferred" and rating all others relative to it. The rating procedure would certainly make this possible. The results of Day (1968) emphasize the influence of the instructional set upon the ratings of the $S$. He has reported curves with differential characteristics depending on whether the S was rating the stimuli as "pleasing" or "interesting." The most plausible alternative resolution would be that the range of complexity was not sufficient to give adequate opportunity for the wide variation in peak preferences to be manifested. Therefore, a next step would be to extend the range of complexity; this would be a straightforward procedure with the Vargus 9 program. With the extended range of complexity, results similar to those of Vitz (1966) and Dorfman \& McKenna (1966) might be expected.

It would seem from the results of the present study, and the results of Vitz (1966) and Dorfman \& McKenna (1966), that it

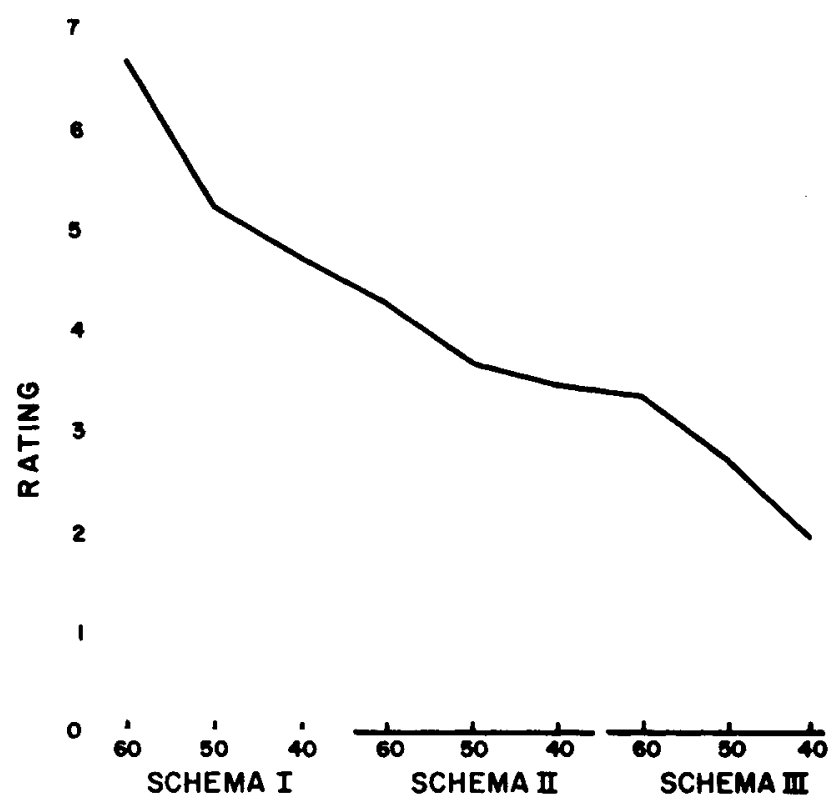

Fig. 2. The preference curve for $S s(N=17)$ who preferred the lowest level of complexity.

would behoove any investigator working in this area to inspect his obtained data for possible individual differences.

\section{REFERENCES}

ATTNEAVE, F., \& ARNOULT, M. D. The quantitative study of shape and pattern perception. Psychological Bulletin, 1956, 53, 452-471.

BARRON, F., \& WELSH, G. S. Artistic perception as a possible factor in personality style: Its measurement by a figure preference test. Journal of Psy chology, 1952, 33, 199-203.

BERLYNE, D. E. Conflict, arousal, and curiosity. New York: McGraw-Hill, 1960.

DAY, H. The importance of symmetry and complexity in the evaluation of complexity, interest and pleasingness. Psychonomic Science, 1967, 7, 147-148.

DEMBER, W. N., \& EARL, R. W. Analysis of exploratory, manipulatory and curiosity behavior. Psychological Review, 1957, 64, 91-96.

DORFMAN, D. D., \& McKENNA, H. Pattern preference as a function of pattern uncertainty. American Joumal of Psychology, 1966, 20, 143-153.

EVANS, S. H. A brief statement of schema theory. Psychonomic Science, $1967,8,87-88$.

EVANS, S. H., \& MUELLER, M. R. Vargus 9: Computed stimuli for schema research. Psychonomic Science, 1966, 6, 511-512.

HERSHENSON, M., MUNSINGER, H., \& KESSEN, W. Preference for shapes of intermediate variability in the newborn human. Science, $1965,147,630-631$.

KAMMANN, R. Verbal complexity and preferences in poetry. Journal of Verbal Learning \& Verbal Behavior, 1966, 5, 536-540.

LANE, S. H., \& EVANS, S. H. Judged complexity of Vargus 9 generated stimuli. Psychonomic Science, 1968, 11, 45-46.

MUNSINGER, $H$, \& KESSEN, W. Uncertainty, structure, and preference. Psychological Monographs: General \& Applied, 1964, 78 (Whole No. 596), 1-24.

MUNSINGER, H., KESSEN, W., \& KESSEN, M. L. Age and uncertainty: Developmental variation in preference for variability. Journal of Experimental Child Psychology, 1964, 1, 1-15.

MUNSINGER, H., \& WEIR, $M$, W. Infant's and young children's preference for complexity. Journal of Experimental Child Psychology, $1967,5,69-75$.

THOMAS, H. Preferences for random shapes: Ages six through nineteen years. Child Development, $1966,37,843-859$.

VITZ, P. Preference for different amounts of visual complexity. Behavioral Science, 1966, 11, 105-114.

WELSH, G. S. Preliminary manual, Welsh, figure preference test (Research ed.). Palo Alto: Consulting Psychologists Press, 1959. NOTE

1. The author expresses gratitude to Dr. S. H. Evans of the Institute for the Study of Cognitive Systems for his assistance in this study. This research was supported in part by Veterans Rehabilitation Services Grant

RAS 2 to the Institute of Behavioral Research and, in part, by Department of Defense Project THEMIS Contract No. DAADO568-C-0176 under the Department of the Army 